\title{
Neuromuscular Blocking Properties of Dantrolene at the Neuromuscular Junction and Its Recovery with Various Antagonists
}

\author{
Sung Yell Kim, M.D., and Jeong Seok Lee, M.D. \\ Department of Anesthesiology, College of Medicine, \\ Soon Chun Hyang University and Hospital, Seoul, Korea
}

\section{$=$ Abstract $=$}

Background: Dantrolene produces skeletal muscle relaxation by a direct action on excitation-contraction coupling, presumably by decreasing the amount of calcium released from the sarcoplasmic reticulum. The mechanism underlying this action is extrajunctional. The aim of this study was to evaluate the pharmacodynamic properties of dantrolene at the neuromuscular junction and the reversal effects of substances as possible dantrolene antagonists in vitro.

Methods: The effects of evoked twitch tension response have been studied on the isolated phrenic nerve hemidiaphragm muscle strips of the rat, using a single twitch $(0.1 \mathrm{~Hz})$ and the train of four (TOF; $2 \mathrm{~Hz}$ for $2 \mathrm{~s})$ stimulation. The maximum effect $\left(\mathrm{E}_{\mathrm{max}}\right)$ and TOF ratio at each point of twitch depression after cumulative doses of dantrolene were measured mechanomyographically. The $\mathrm{EC}_{50}$ and $\mathrm{EC}_{95}$ of dantrolene were calculated using an inhibitory sigmoid $\mathrm{E}_{\max }$ model. The reversal effect to $\mathrm{E}_{\max }$ after administration of $10 \mathrm{mM}$ of dantrolene was determined by various doses of neostigmine, pyridostigmine or 4-aminopyridine respectively.

Results: The $\mathrm{E}_{\max }$ was $76.14 \%$ of the initial twitch tension, but the residual twitch tension was remained until five times $(10 \mathrm{mM})$ of the dose for the $\mathrm{E}_{\max }$ was administered. TOF stimulation to the residual twitch tension did not demonstrate any fade. The $\mathrm{EC}_{50}$ and $\mathrm{EC}_{95}$ of dantrolene were 0.379 and $3.177 \mathrm{mM}$ respectively. Neostigmine and pyridostigmine produced a transient but incomplete recovery of twitch tension, which rapidly fell to the level of the twitch response before the drugs were given. However, 4-aminopyridine produced a dose-dependent recovery of the twitch response. The addition of neostigmine $(0.5 \mathrm{mg} / \mathrm{ml})$ or pyridostigmine $(2.5 \mathrm{mg} / \mathrm{ml})$ did not decrease the $\mathrm{EC}_{50}$ and $\mathrm{EC}_{95}$ of 4-aminopyridine in reversing the effect of dantrolene.

Conclusions: These results have demonstrated the evidence that dantrolene did not completely depress the twitch tension, leaving if at nearly $25 \%$, and accompanying TOF response without fade, and that anticholinesterases were ineffective in antagonizing its blockade. However, 4-aminopyridine was effective and may not be related to the propensity for pre- and postjunctional cholinergic receptor blockade at the neuromuscular junction. (Korean J Anesthesiol 2001; 41: S 1 S 6)

Key Words: Antagonists, neuromuscular relaxants: neostigmine; pyridostigmine; 4-aminopyridine. Neuromuscular relaxants: dantrolene.

Received : July 30, 2001

Corresponding to : Jeong Seok Lee, Department of Anesthesiology, Soon Chun Hyang Hospital Bucheon, 1174 Jung-dong, Wonmi-gu, Bucheon, Gyeonggi-do, Korea

Tel: 032-621-5326, Fax: 032-621-5016, E-mail: juju1218@dreamwiz.com 


\section{INTRODUCTION}

The main interest of anesthetists in dantrolene lies in its potential value in countering various forms of muscle spasticity. ${ }^{1)}$ Flewellen et al predicted that large dose of dantrolene would be effective in the treatment and prophylaxis of malignant hyperthermia. ${ }^{2)}$ In the initial treatment of acute malignant hyperthermia the rapid intravenous administration is recommended. In spite of large loading doses significant neuromuscular blockade has not been experienced. However, although previous studies have not revealed an alteration in neuromuscular transmission or in the electrical properties of the skeletal muscle membranes, ${ }^{3)}$ dantrolene has been reported to cause a dosedependent depression of skeletal muscle contractility.,4) Watson et al found that patients treated with dantrolene complained of significant muscle weakness after taking the drug. ${ }^{5)}$ It appears that dantrolene can induce a major negative inotropic effect on normal skeletal muscle. The impairment of muscle contraction may cause respiratory failure and have important consequences in clinical practice. $\left.{ }^{6}\right)$ Thus dantrolene is a skeletal muscle relaxant named as 1-[\{5-Arylfurfurylidene $\}$ amino] hydantoins and suppresses the release of the calcium from the sarcoplasmic reticulum into the sarcoplasm, thereby indirectly impairing the activation of myosin ATPase and the formation of cross-bridges. The site of action appears to be transverse tubules ( $\mathrm{T}$ tubules), where dantrolene may act to inhibit the release of trigger calcium by an action potential, and consequently prevent all subsequent stages of the excitation-contraction coupling sequence. ${ }^{7)}$ It means that the pharmacological site of action of dantrolene, which underlies this effect, is extrajunctional. Therefore we have carried out this study to evaluate the neuromuscular blocking properties at the neuromuscular junction and its recovery with various antagonists in the rat phrenic nerve-hemidiaphragm preparation.

\section{METHODS}

This study was performed in accordance with the
Animal Care and Use Committee of Soon Chun Hyang University and Hospital. The electrolyte composition of freshly prepared Krebs solution consisted of $\mathrm{NaCl}_{2} 118$, $\mathrm{KCl} 4.7, \mathrm{MgSO}_{4} 1.2, \mathrm{KH}_{2} \mathrm{PO}_{4} 1.1, \mathrm{NaHCO}_{3} 25, \mathrm{CaCl}_{2} 2.5$, and glucose $11 \mathrm{mM}$ in daily highly purified water. This solution was maintained in a $100 \mathrm{ml}$ jacketed organ bath at $32^{\circ} \mathrm{C}$ with a thermostatic water circulator (WB-20D, Jeio Tech Co., LTD., Korea). The temperature of the solution was continuously monitored. Five percent $\mathrm{CO}_{2}$ in $\mathrm{O}_{2}$ was bubbled through the water bath to maintain a $\mathrm{pH}$ of approximately 7.4. Sprague-Dawley rats, weighing between 250 and $300 \mathrm{~g}$, were anesthetised with 1 to $3 \mathrm{ml}$ of $2.5 \%$ thiopentone sodium intraperitoneally and the diaphragms with their accompanying phrenic nerves were dissected out, trimmed and halved, to give two separate hemidiaphragms. The lower aspect of the rib cage was fixed to the specially designed holder and the hemidiaphragm was suspended, at the central tendon, from a Grass FT 03 force displacement transducer (Grass Instruments Co., USA) that had been pretensioned to $7 \mathrm{~g}$. The phrenic nerve was positioned on wire bipolar platinum stimulating electrodes in the holder that also fixed the hemidiaphragm strip. It was stimulated with a Grass S88 stimulator (Grass Instruments Co.) using supramaximal square wave stimuli of $0.2 \mathrm{~ms}$ duration at a frequency of $0.1 \mathrm{~Hz}$. The evoked twitch tension was recorded using the force transducer on a Grass Polygraph Model 79 recorder. Each preparation was allowed to stabilize for at least $30 \mathrm{~min}$ or until a stable single twitch and train of four (TOF; $2 \mathrm{~Hz}$ for 2 s) response was established. All drugs used (Dantrolene sodium; Procter \& Gamble Pharmaceuticals, UK, Neostigmine; Sigma Chemical, St. Louis, MO, USA, Pyridostigmine; Sigma, 4-Aminopyridine; Sigma) were administered from a precision microliter pipette (Pipetman, Gilson Medical Electronics, France) into the water bath. Each experimental group consisted of 5 to 7 preparations of different hemidiaphragms. Every diaphragm was exposed to effective concentrations (EC) of dantrolene in the range from 0.01 to $10.0 \mathrm{mM}$ (Fig. 1). The depression of the single twitch tension from the baseline height and TOF response at each $\mathrm{EC}$ of dantrolene was recorded. The response to each EC was considered stable when evoked 
twitch responses was of the same height for 2 or $3 \mathrm{~min}$. The percentage change in the twitch tension and maximum effect $\left(E_{\max }\right)$, accompanying TOF ratios, were measured, and dose response curves for dantrolene were plotted using $\log$ effective concentration scale. ${ }^{8)}$ Effective concentrations expected to produce 50 and $95 \%$ blockade $\left(\mathrm{EC}_{50}, \mathrm{EC}_{95}\right)$ of dantrolene were calculated by inhibitory sigmoid $\mathrm{E}_{\max }$ model; $y=y_{0}-\left(E_{\max } \times x^{r}\right) /\left(E C_{50}{ }^{r}+x^{r}\right)$, from computer software SigmaPlot Windows version 4.0 (SPSS Inc, USA).

When maximum depression of the twitch tension induced by dantrolene $10 \mathrm{mM}$ was stabilized for at least $15 \mathrm{~min}$, various equipotent doses of neostigmine, pyridostigmine or 4-aminopyridine, calculated from the relationship between dose and response for these three reversal agents obtained the an earlier study, ${ }^{9}$ ) were added as a bolus into the organ bath. Dose response curves were determined for neostigmine, pyridostigmine and 4-aminopyridine respectively. Neostigmine $(0.5 \mathrm{mg} / \mathrm{ml})$ or pyridostigmine $(2.5 \mathrm{mg} / \mathrm{ml})$ was then combined with various doses of 4-aminopyridine in order to determine whether the $\mathrm{EC}_{50}$ and $\mathrm{EC}_{95}$ of 4-aminopyridine were altered.

Statistical analysis was performed using SPSS. Results were compared using Kruskal-Wallis one-way analysis of variance (ANOVA) and groups, which differed significantly by ANOVA, were tested with Student-Newman-Keuls multiple range test to determine differences between groups. The TOF ratio at every EC of dantrolene up to the $\mathrm{E}_{\mathrm{max}}$ was compared with the initial TOF ratio in each group, using the paired Student's t test. Differences were considered statistically significant at $\mathrm{P}<0.05$. Data are expressed as mean $\pm \mathrm{SD}$ of each group and as $\mathrm{mM}$ or percent of control.

\section{RESULTS}

Twitch tensions and TOF ratios measured at each EC of dantrolene in the range from 0.01 to $10.0 \mathrm{mM}$ are shown in Fig. 1. A significant difference in the mean twitch tension was observed with doses of dantrolene between doses of 0.05 and $2.0 \mathrm{mM}$. No significant

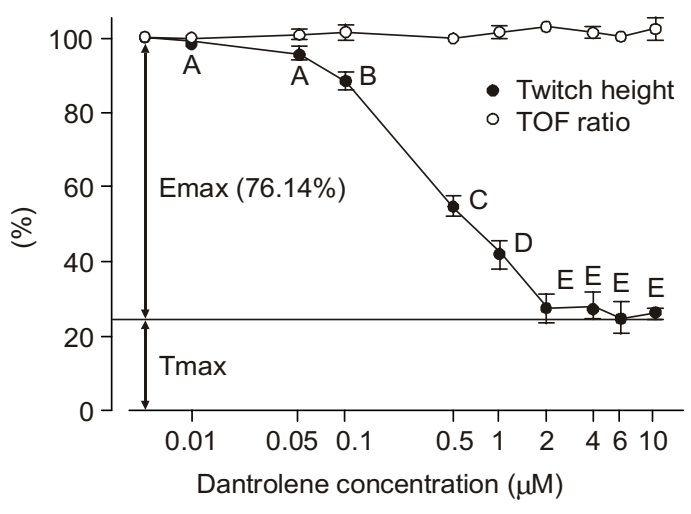

Fig. 1. Cumulative $\log$ concentration-response curve of dantrolene in the rat diaphragm: the percent (\%) means the changes of twitch tension (closed circle) and train of four ratio (open circle). The vertical lines at each concentration response point represent the mean \pm SD. $\mathrm{E}_{\max }$ indicates maximum effect (maximum depression of twitch tension), leaving residual twitch height $\left(\mathrm{T}_{\max }\right)$ after dantrolene was given. Means with different letters (A, B, C, $D, E)$ indicate significant difference between groups for each variable $(\mathrm{P}<0.05$, Student-Newman-Keuls).

changes in the mean twitch tension occurred for doses of dantrolene in the range from 0.01 to $0.05 \mathrm{mM}$ and in the range from 2.0 to $10.0 \mathrm{mM}$. $\mathrm{E}_{\max }$ was $76.14 \%$, leaving the residual twitch tension $\left(\mathrm{T}_{\max }\right) . \mathrm{T}_{\max }$ which was maximally depressed by $2.0 \mathrm{mM}$ is $27.3 \pm 3.8 \%$ and it is resistant as $25.7 \pm 1.5 \%$ in the increasing dose to $10.0 \mathrm{mM}$. The $\mathrm{EC}_{50}$ and the $\mathrm{EC}_{95}$ for twitch depression were 0.379 and $3.177 \mathrm{mM}$ respectively. All four responses to TOF stimulation were sustained and TOF ratio did not alter at any dose of dantrolene or any magnitude of twitch depression.

Details of the effect of reversal agents on the dantrolene block are given in Table 1. At the maximum depression of the twitch tensions produced by a dose of dantrolene $10.0 \mathrm{mM}$, administration of neostigmine and pyridostigmine produced a slight and transient increase of twitch tension followed by rapid rundown to the initial level. Therefore, since these results were not consistent with a dose response effect (Table 1), the dose response curves were not determined for neostigmine and pyridostigmine. However, administration of 4-aminopyridine produced a dose-dependent recovery (Table 1). The $\mathrm{EC}_{50}$ and $\mathrm{EC}_{95}$ for 
Table 1. Twitch Tensions $\left(\mathrm{R}_{\max }\right)$ Which are Reversed by Various Doses of Neostigmine, Pyridostigmine or 4-Aminopyridine at the Maximally Depressed Twitch Tensions $\left(\mathrm{T}_{\max }\right)$ after Administration of Dantrolene $(10 \mathrm{mM})$, and the Difference between $R_{\max }$ and $\mathrm{T}_{\max }\left(\mathrm{R}_{\max }-\mathrm{T}_{\max }\right)$

\begin{tabular}{cccc}
\hline \hline Reversal agents $(\mu \mathrm{g} / \mathrm{ml})$ & $\mathrm{T}_{\max }(\%)$ & $\mathrm{R}_{\max }(\%)^{*}$ & $\mathrm{R}_{\max }-\mathrm{T}_{\max }$ \\
\hline Neostigmine & & & \\
$0.125 \quad(\mathrm{n}=5)$ & $26.8 \pm 2.3$ & $31.5 \pm 5.0^{\mathrm{A}}$ & $4.7 \pm 2.7^{\mathrm{A}}$ \\
$0.25 \quad(\mathrm{n}=6)$ & $27.4 \pm 2.5$ & $38.4 \pm 7.1^{\mathrm{B}}$ & $11.0 \pm 6.1^{\mathrm{B}}$ \\
$0.5 \quad(\mathrm{n}=6)$ & $28.8 \pm 6.3$ & $54.4 \pm 1.0^{\mathrm{C}}$ & $25.6 \pm 4.9^{\mathrm{C}}$ \\
$1.0 \quad(\mathrm{n}=7)$ & $29.0 \pm 2.6$ & $36.8 \pm 3.8^{\mathrm{B}}$ & $7.8 \pm 4.5^{\mathrm{AB}}$ \\
Pyridostigmine & & & \\
$0.625 \quad(\mathrm{n}=6)$ & $29.7 \pm 3.1$ & $39.7 \pm 5.4^{\mathrm{A}}$ & $10.0 \pm 4.4^{\mathrm{A}}$ \\
$1.25 \quad(\mathrm{n}=5)$ & $28.3 \pm 0.9$ & $41.0 \pm 1.9^{\mathrm{A}}$ & $12.7 \pm 1.9^{\mathrm{A}}$ \\
$2.5 \quad(\mathrm{n}=6)$ & $27.5 \pm 4.8$ & $47.4 \pm 8.2^{\mathrm{B}}$ & $20.0 \pm 5.3^{\mathrm{B}}$ \\
$5.0 \quad(\mathrm{n}=7)$ & $28.6 \pm 3.2$ & $48.3 \pm 9.8^{\mathrm{B}}$ & $19.8 \pm 7.9^{\mathrm{B}}$ \\
$4-$ Aminopyridine & & & \\
$1.0 \quad(\mathrm{n}=6)$ & $29.3 \pm 5.9$ & $47.0 \pm 5.6^{\mathrm{A}}$ & $17.6 \pm 3.2^{\mathrm{A}}$ \\
$2.0 \quad(\mathrm{n}=6)$ & $29.5 \pm 3.3$ & $56.7 \pm 6.1^{\mathrm{B}}$ & $27.2 \pm 9.1^{\mathrm{B}}$ \\
$4.0 \quad(\mathrm{n}=6)$ & $28.2 \pm 3.2$ & $81.1 \pm 5.5^{\mathrm{C}}$ & $55.4 \pm 7.3^{\mathrm{C}}$ \\
$8.0 \quad(\mathrm{n}=6)$ & $29.2 \pm 2.4$ & $101.8 \pm 4.2^{\mathrm{D}}$ & $72.6 \pm 3.4^{\mathrm{D}}$ \\
\hline
\end{tabular}

Values are mean $\pm \mathrm{SD}$. ${ }^{*}$ The numerical values of $\mathrm{R}_{\max }$ in various doses of neostigmine or pyridostigmine followed by rapid rundown to the level $\left(T_{\max }\right)$ before drugs were given. Means with different letters $(A, B, C, D)$ indicate significant difference between doses of each reversal agent for each variable $(P<0.05$, Student-Newman-Keuls).

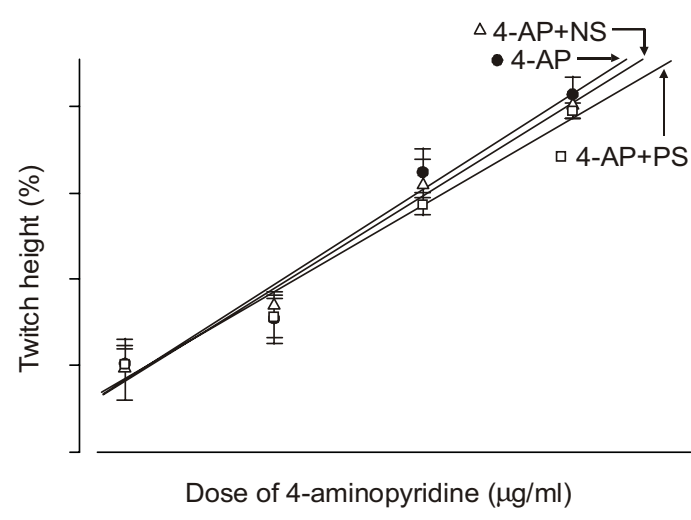

Fig. 2. The lines represent analysis of linear regression of reversal effects of 4-aminopyridine alone $(4-\mathrm{AP})$, and given with neostigmine $(\triangle 4-\mathrm{AP}+\mathrm{NS}, 2.5 \mathrm{mg} / \mathrm{ml})$ or pyridostigmine ( $\square$-AP + PS, $0.5 \mathrm{mg} / \mathrm{ml}$ ) on percent (\%) of antagonism from maximum depressed twitch tension after dantrolene $(10 \mathrm{mM})$ was given. The vertical lines represent the mean $\pm \mathrm{SD}$.

4-aminopyridine were $2.07 \mathrm{mg} / \mathrm{ml}$ and $6.42 \mathrm{mg} / \mathrm{ml}$ (Fig. 2). The $\mathrm{EC}_{50}$ and $\mathrm{EC}_{95}$ values in the combination of 4-aminopyridine with neostigmine $(0.5 \mathrm{mg} / \mathrm{ml})$ or pyrido- stigmine $(2.5 \mathrm{mg} / \mathrm{ml})$ were $2.102 \mathrm{mg} / \mathrm{ml}$ and $6.77 \mathrm{mg} / \mathrm{ml}$, or $2.208 \mathrm{mg} / \mathrm{ml}$ and $7.55 \mathrm{mg} / \mathrm{ml}$. Thus addition of neostigmine or pyridostigmine did not decrease the $\mathrm{EC}_{50}$ and $\mathrm{EC}_{95}$ of 4-aminopyridine (Fig. 2).

\section{DISCUSSION}

When anesthetists use the term of muscle relaxation produced by neuromuscular blocking agents it usually refers to pre- and postsynaptic cholinergic receptor block at the neuromuscular junction. However, skeletal muscle relaxation can result to interfere with the passage of impulses at any point of the steps from the motor nerve to skeletal muscle. Unlike neuromuscular blocking agents, dantrolene depressed muscle activity after the generation of a muscle endplate action potential by acetylcholine releasing from the vesicle in the nerve ending. It acts in the muscle contraction coupling sequence. ${ }^{10)}$ As a result the action potential remains unaltered but it fails to trigger contraction of the muscle. The experimental evidence indicates that dantrolene acts by inhibiting the release of $\mathrm{Ca}^{++}$ 
from the sarcoplasmic reticulum into the sarcoplasm impairing the activation of myosin ATPase and the formation of the cross-bridges which result in muscle contraction. ${ }^{7,11)}$ By inhibiting the release of trigger $\mathrm{Ca}^{++}$ by the action potential, dantrolene prevents all the subsequent stages of the excitation-contraction coupling sequence. Thus, although the site of action of dantrolene is extrajunctional, this study was investigated in order to confirm the neuromuscular blocking properties of dantrolene at the neuromuscular junction.

In our study we have found that twitch tension depression caused by dantrolene occurred in the cumulative dose range of 0.01 to $2.0 \mathrm{mM}$. The $\mathrm{E}_{\max }$ was $76.14 \%$, leaving a $\mathrm{T}_{\max }$ that was resistant to dantrolene in spite of administering five times $(10.0 \mathrm{mM})$ the dose that produced the maximum depression (Fig. 1). The questions arise as to why there is a resistant residual twitch tension. It has been suggested that a variable part of the excitationcontraction coupling sequence bypasses the site of action of dantrolene. Another possible explanation is that although the first muscle action potential fails to release sufficient $\mathrm{Ca}^{++}$to activate the contractile mechanism, in the presence of dantrolene, it causes some of the remaining $\mathrm{Ca}^{++}$to be placed in a precarious or less strongly bound state, making it available in response to subsequent action potentials. It is also possible that a small part of the $\mathrm{Ca}^{++}$involved in muscle contraction is derived from a source other than the $\mathrm{T}$ tubule-triad-sarcoplasmic reticulum system which is thought to be the site of action of dantrolene, ${ }^{12)}$ such as the mitochondria. ${ }^{13)}$ The diaphragm contains a high content of mitochondria ${ }^{14)}$ and mitochondrial $\mathrm{Ca}^{++}$has been found to play a more important role in the contractile activity in this muscle. In the results of this study, the presence of a resistant residual twitch tension in spite of the loading doses of dantrolene suggests that postsynaptic cholinergic receptors are not blocked. On the other hand TOF fade is generally attributed to a presynaptic blocking effect causing a progressive decrease in acetylcholine release from the nerve ending. ${ }^{15)}$ The generally accepted view is that the degree of fade is related to presynaptic binding and the demonstration of fade is taken as evidence of presynaptic cholinergic receptor block. ${ }^{16)}$ In our study, the evidence that TOF fade did not occur at the maximum twitch depression means that dantrolene may not have a presynaptic effect at the neuromuscular junction.

4-aminopyridine produces more greater reversal effect to dantrolene blockade in extrajunctional than in intrajunctional. Furthermore 4-aminopyridine potentiates antagonism of a pancuronium induced neuromuscular blockade by neostigmine or pyridostigmine. ${ }^{20)}$ However, we have demonstrated that the combination of neostigmine or pyridostigmine with 4-aminopyridine fails to reduce the $\mathrm{EC}_{50}$ and $\mathrm{EC}_{95}$ of 4-aminopyridine. It means that the concentration of acetylcholine increased by neostigmine or pyridostigmine does not altered the dantrolene block.

Consequently, the results of this study suggest that the hypothesis that the neuromuscular blocking action produced by dantrolene was not associated with pre- and postsynaptic cholinergic receptor block at the neuromuscular junction and was due to directly suppressing the skeletal muscle contraction may be true, using the isolated rat diaphragm preparation. However, this is in keeping with expectation that although the cholinergic receptors at neuromuscular junction are not affected, dantrolene may interfere with ventilation as a result of muscle relaxation not to antagonised with anticholinesterases. Therefore when rapid intravenous use of large dose of dantrolene is recommended special care should be taken to monitor and managed under the supervision.

\section{ACKNOWLEDGMENTS}

We thank Professor Emeritus Stanley A. Feldman, Magill Department of Anaesthetics, Westminster Medical School, University of London, for his invaluable help with this study and manuscript preparation.

\section{REFERENCES}

1. Duncan PG: Availability of dantrolene in Canadian hospitals. Can Anaesth Soc J 1985; 32: 205-9.

2. Flewellen EH, Nelson TE, Jones WP, Arens JF, Wagner DL: Dantrolene dose response in awake man: Implications for management of malignant hyper- 
thermia. Anesthesiology 1983; 59: 275-80.

3. Davidoff RA: Pharmacology of spasticity. Neurology (Minneapolis) 1978; 28: 46-51.

4. Kolb ME, Horne ML, Martz R: Dantrolene in human malignant hyperthermia. Anesthesiology 1982; 56: 254-62.

5. Watson $\mathrm{CB}$, Reierson N, Norfleet EA: Clinically significant muscle weakness induced by oral dantrolene sodium prophylaxis for malignant hyperthermia. Anesthesiology 1986; 65: 312-4.

6. Rochester DF: The diaphragm: contractile properties and fatigue. J Clin Invest 1985; 75: 1397-402.

7. Putney JW, Bianchi CP: Site of action of dantrolene in frog sartorius muscle. J Pharmacol Exp Ther 1974; 189: 202-12.

8. Bevan DR, Bevan JC, Donati F: Muscle relaxants in clinical anesthesia. Chicago, Year Book Medical Publishers INC. 1988, pp 71-99.

9. Okamoto T, Aoki T, Fukushima K, Yoneda I, Satoh $\mathrm{T}$, Nagashima $\mathrm{H}$ : Neuromuscular blocking effect of ORG 9426, a new nondepolarizing muscle relaxant, and its recovery with various antagonists in vitro. Masui 1992; 41: 1467-73.

10. Van Winkle WB: Calcium release from skeletal muscle sarcoplasmic reticulum; site of action of dantrolene sodium. Science 1976; 193: 1130-1.

11. Oba T, Hotta K: Transient effect of intracellular dantrolene on E-C coupling in skeletal muscle. Eur J Pharmacol 1978; 51: 81-4.

12. Bowman WC, Houston J, Khan HH, Rodger IW: Effects of dantrolene sodium on respiratory and other muscles and on respiratory parameters in the anaesthetised cat. Eur J Pharmacol 1979; 55: 293-303.

13. Dransfeld H, Greeff K, Schorn A, Ting BT: Calcium uptake in mitochondria and vesicles of heart and skeletal muscle in presence of potassium, sodium, k-strophanthin and pentobarbiral. Biochem Pharmacol 1969; 18: 1335-45.

14. Batra S: The effects of zinc and lanthanum on calcium uptake by mitochondria and fragmented sarcoplasmic reticulum of frog skeletal muscle. J Cell Physiol 1973; 82: $245-56$

15. Kim SY, Lee JS, Kim SC, Park W: Twitch augmentation and train-of-four fade during onset of neuromuscular block after subclinical doses of suxamethonium. Br J Anaesth 1997; 79: 379-81.

16. Feldman S, Hood J: Depolarizing neuromuscular blocka presynaptic mechanism? Acta Anaesthesiol Scand 1994; 38: 535-41.

17. Riker WF, Okamoto MO: Pharmacology of motor nerve terminals. Annu Rev Pharmacol 1969; 9: 173-208.

18. Bowman WC, Khan HH, Savage AO: Some antagonists of dantrolene sodium on the isolated diaphragm muscle of the rat. J Pharm Pharmacol 1977; 29: 616-25.

19. Agoston S, Bowman WC, Houwertjes MC, Rodger IW, Savage AO: Direct action of 4-aminopyridine on the contractility of a fast contracting muscle in the cat. Clin Exp Pharmacol Physiol 1982; 9: 21-34.

20. Miller RD, Booij LHC, Agoston S, Crul JF: 4Aminopyridine potentiates neostigmine and pyridostigmine in man. Anesthesiology 1979; 50: 416-20. 